\title{
On Completely E*-Irresolute and Completely Weakly E*- Irresolute Functions in Topological Spaces via $\mathrm{E}^{*}$-open sets
}

\author{
Alaa. M. F. Al. Jumaili and Xiao-Song Yang
}

\begin{abstract}
The main aim of this paper is to introduce and investigate two new classes of irresolute functions called

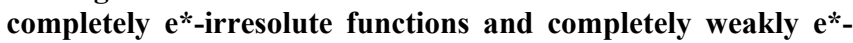
irresolute functions in topological spaces by using the concept of $e^{*}$-open sets was introduced by Erdal Ekici [1], and obtain some characterizations and several interesting properties concerning such these functions. Furthermore the relationships between these functions and some other types of continuous functions are also given.
\end{abstract}

Index Terms- $\mathrm{E}^{*}$-Open Sets, $\mathrm{e}^{*}$-irresolute functions, completely $\mathrm{e}^{*}$-irresolute functions, completely weakly $\mathrm{e}^{*}$ irresolute functions.

\section{INTRODUCTION}

Many different forms of irresolute functions have been introduced over the course of years. Certainly, it is hard to say whether one form is more or less important than another. Functions and of course irresolute functions stand among the most important and most researched points in the whole of mathematical science. In 1972, Crossley and Hildebrand [2] introduced the notion of irresoluteness. Various interesting problems arise when one considers irresoluteness Its importance is significant in various areas of mathematics and related sciences. In 2009, Erdal Ekici [1] introduced a new class of generalized open sets called $e^{*}$-open sets and studied several fundamental and interesting properties of $\mathrm{e}^{*}$ open sets and introduced a new class of continuous functions called $\mathrm{e}^{*}$-continuous functions into the field of topology. Recently, in 2011, N. Rajesh [3] introduced two new types of irresolute functions via b-open sets. The purpose of this paper is to introduce and investigate other new types of irresolute functions via $\mathrm{e}^{*}$-open sets called completely $\mathrm{e}^{*}$-irresolute functions and completely weakly $\mathrm{e}^{*}$-irresolute functions. Some characterizations and several properties concerning such these functions are obtained.

\section{PRELIMINARIES}

Throughout this paper, $(\mathrm{X}, \mathrm{T})$ and $\left(\mathrm{Y}, \mathrm{T}^{*}\right)$ (or simply $\mathrm{X}$ and $\mathrm{Y}$ ) mean topological spaces on which no separation axioms are assumed unless explicitly stated. For any subset $\mathrm{A}$ of $\mathrm{X}$, The closure and interior of $\mathrm{A}$ are denoted by $\mathrm{Cl}(\mathrm{A})$ and $\operatorname{Int}(\mathrm{A})$, respectively.

A subset $A$ of a space $(X, T)$ is called $\delta$-open [4] if for each $\mathrm{x} \in \mathrm{A}$ there exists a regular open set $\mathrm{V}$ such that

Manuscript received May 18, 2012; revised June 12, 2012

The authors are with Department of Mathematics, Huazhong University of Science and Technology, Wuhan, 430074, China (e-mail: (alaa_mf1970@yahoo.com). $x \in V \subset A$. The $\delta$-interior of $\mathrm{A}$ is the union of all regular open sets contained in $\mathrm{A}$ and is denoted by $\operatorname{Int} \delta(A)$. The subset $\mathrm{A}$ is called $\delta$-open [4] if $A=\operatorname{Int} \delta(A)$. A point $\mathrm{x} \in \mathrm{X}$ is called a $\delta$-cluster points of A [4] if $A \cap \operatorname{Int}(C l(V)) \neq \varnothing$ for each open set $\mathrm{V}$ containing $\mathrm{x}$. The set of all $\delta$-cluster points of $\mathrm{A}$ is called the $\delta$-closure of $\mathrm{A}$ and is denoted by $C l \delta(A)$. If $A=C l \delta(A))$, then $\mathrm{A}$ is said to be $\delta$-closed [4]. The complement of $\delta$-closed set is said to be $\delta$-open set.

A subset A of a space $\mathrm{X}$ is called $e^{*}$-open [1] if $A \subset C l(\operatorname{Int}(C l \delta(A)))$, the complement of an $e^{*}$-open set is called $\mathrm{e}^{*}$-closed. The intersection of all $\mathrm{e}^{*}$-closed sets containing $\mathrm{A}$ is called the $\mathrm{e}^{*}$-closure of A [1] and is denoted by $e^{*}-C l(A)$. The union of all $\mathrm{e}^{*}$-open sets of $\mathrm{X}$ contained in $\mathrm{A}$ is called the $\mathrm{e}^{*}$-interior [1] of $\mathrm{A}$ and is denoted by $e^{*}$ $\operatorname{Int}(A)$.

A subset $\mathrm{A}$ is said to be regular open (resp. regular closed) [5] if $A=\operatorname{Int}(C l(A))(\operatorname{resp} . A=C l(\operatorname{Int}(A)))$.

The family of all regular open (resp. regular closed, e*open, $\mathrm{e}^{*}$-closed) subsets of $\mathrm{X}$ containing a point $\mathrm{x} \in \mathrm{X}$ is denoted by $R O(X, x)$ (resp. $\left.R C(X, x) E^{*} \Sigma(X, x), E^{*} C(X, x)\right)$. The family of all regular open (resp. regular closed, $\mathrm{e}^{*}$-open, $\mathrm{e}^{*}$-closed) sets in $\mathrm{X}$ are denoted by $R O(X, T)$ (resp. $R C(X$, $\left.T), E^{*} \Sigma(X, T), E^{*} C(X, T)\right)$.

\section{CHARACTERIZATIONS OF COMPLETELY E* IRRESOLUTE FUNCTIONS}

In this section, we obtain some characterizations and several properties concerning completely $\mathrm{e}^{*}$-irresolute functions.

\section{A. Definition.}

A function $\mathrm{f}:(\mathrm{X}, \mathrm{T}) \rightarrow\left(\mathrm{Y}, \mathrm{T}^{*}\right)$ is said to be:

1) strongly continuous [6] if $f-1(V)$ is both open and closed in $\mathrm{X}$ for each subset $\mathrm{V}$ of $\mathrm{Y}$;

2) completely continuous [7] if $f-1(V)$ is regular open in $\mathrm{X}$ for each open set $\mathrm{V}$ of $\mathrm{Y}$;

3) $\mathrm{e}^{*}$-continuous $[1]$, if $\mathrm{f}-1(\mathrm{~V})$ is $\mathrm{e}^{*}$-open in $\mathrm{X}$ for every open set $\mathrm{V}$ of $\mathrm{Y}$.

4) $\mathrm{e}^{*}$-irresolute $[8]$ if $\mathrm{f}-1(\mathrm{~V}) \in \mathrm{E}^{*} \Sigma(\mathrm{X}, \mathrm{T})$ for every $\mathrm{V} \in \mathrm{E}^{*} \Sigma(\mathrm{Y}, \mathrm{T})$.

5) Completely $\mathrm{e}^{*}$-irresolute if the inverse image of every $\mathrm{e}^{*}$-open subset of $\mathrm{Y}$ is regular open in $\mathrm{X}$.

\section{B. Remark}

It is clear that, every strongly continuous function is completely $\mathrm{e}^{*}$-irresolute and every completely $\mathrm{e}^{*}$-irresolute function is $\mathrm{e}^{*}$-irresolute function. However, the converses of the implications are not true in general as shown in the 
following examples.

\section{Example}

Let $X=Y=\{1,2,3\}$, Define a topology $T=\{\varnothing, X,\{1\},\{2$, $3\}\}$ on $\mathrm{X}$ and a topology $T^{*}=\{\varnothing, Y,\{1\}\}$ on $\mathrm{Y}$. Then the identity function $\mathrm{f}:(X, T) \rightarrow\left(Y, T^{*}\right)$ is completely $\mathrm{e}^{*}$ irresolute but not strongly continuous.

\section{Example}

Let $X=Y=\{1,2,3\}$, Define a topology $\mathrm{T}=\{\varnothing, X,\{1,2\}\}$ on $\mathrm{X}$ and a topology $T^{*}=\{\varnothing, Y,\{1\},\{1,2\}\}$ on $\mathrm{Y}$. Then the identity function $f:(X, T) \rightarrow\left(Y, T^{*}\right)$ is $\mathrm{e}^{*}$-irresolute but not completely $\mathrm{e}^{*}$-irresolute.

\section{E. Remark}

From the above arguments, we obtain Figure (1) shown below:

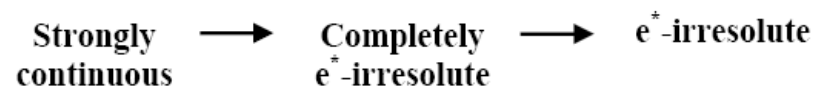

Fig.1

\section{F. Theorem}

For a function $f:(X, T) \rightarrow\left(Y, T^{*}\right)$ the following statements are equivalent:

1) $\mathrm{f}$ is completely $\mathrm{e}^{*}$-irresolute;

2) $f-1(M)$ is regular closed in $\mathrm{X}$ for every $\mathrm{e}^{*}$-closed set $\mathrm{M}$ of $\mathrm{Y}$.

Proof. (a) $\Rightarrow$ (b): Let $\mathrm{M}$ be any e*-closed set of $\mathrm{Y}$. Then $Y \backslash M^{\in} E^{*} \Sigma\left(Y, T^{*}\right)$. By (a), $f-1(Y \backslash M)=X \mid f-1(M) \in R O(X$, $T$ ). We have $f-1(M) \in R C(X, T)$. (b) $\Rightarrow(a)$ : is similar to proof $(a) \Rightarrow$ (b) thus omitted.

\section{G. Lemma}

Let $\mathrm{K}$ be an open subset of a topological space $(\mathrm{X}, \mathrm{T})$. Then the following hold:

1) If $\mathrm{U}$ is regular open in $\mathrm{X}$, then so is $U \cap K$ in the subspace $(K, T K)$.

2) If $B \subset K$ is regular open in ( $\mathrm{K}, \mathrm{TK})$, then there exists a regular open set $\mathrm{U}$ in $(\mathrm{X}, \mathrm{T})$ such that $\mathrm{B}=$ $U \cap K$.

\section{H. Theorem}

If $f:(X, T) \rightarrow\left(Y, T^{*}\right)$ is a completely $\mathrm{e}^{*}$-irresolute function and $\mathrm{A}$ is any open subset of $\mathrm{X}$, then the restriction $f \mid A: A \rightarrow Y$ is completely $\mathrm{e}^{*}$-irresolute.

Proof. Let $\mathrm{M}$ be an $\mathrm{e}^{*}$-open subset of $\mathrm{Y}$. By hypothesis $\mathrm{f}$ $-1(\mathrm{M})$ is regular open in $\mathrm{X}$. Since $\mathrm{A}$ is open in $\mathrm{X}$, it follows from Lemma (3.1) that $(f \mid A)-1(M)=A \cap f-1(M)$, which is regular open in A. Therefore, $\mathrm{f} \mid \mathrm{A}$ is completely $\mathrm{e}^{*}$ irresolute.

\section{Theorem}

For functions $f:(X, T) \rightarrow\left(Y, T^{*}\right)$ and $g:\left(Y, T^{*}\right) \rightarrow(Z$, $\left.T^{* *}\right)$ the following hold:

1) If $\mathrm{f}$ is completely $\mathrm{e}^{*}$-irresolute and $\mathrm{g}$ is $\mathrm{e}^{*}$ irresolute. Then, gof: $X \rightarrow Z$ is completely $\mathrm{e}^{*}$ irresolute;
2) If $\mathrm{f}$ is completely continuous and $\mathrm{g}$ is completely $\mathrm{e}^{*}$-irresolute. Then, gof is completely $\mathrm{e}^{*}$-irresolute;

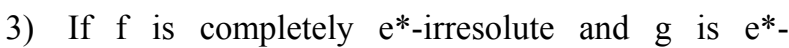
continuous. Then, gof is completely continuous function.

4) If $\mathrm{f}$ is strongly continuous and $\mathrm{g}$ is completely $\mathrm{e}^{*}$ irresolute. Then, gof is completely $\mathrm{e}^{*}$-irresolute.

5) If $f$ and $g$ are completely $e^{*}$-irresolute. Then, gof: $\mathrm{X} \rightarrow \mathrm{Z}$ is completely $\mathrm{e}^{*}$-irresolute.

Proof. The proof is obvious it is follows from their respective definitions thus omitted.

\section{J. Definition}

A space $(\mathrm{X}, \mathrm{T})$ is said to be almost connected [10] (resp. $\mathrm{e}^{*}$-connected [8]) if $\mathrm{X}$ cannot be written as the union of two nonempty disjoint regular open (resp. $\mathrm{e}^{*}$-open) sets.

\section{K. Theorem}

If $f:(X, T) \rightarrow\left(Y, T^{*}\right)$ is a completely $\mathrm{e}^{*}$-irresolute surjective function and $\mathrm{X}$ is almost connected, then $\mathrm{Y}$ is $\mathrm{e}^{*}$ connected.

Proof. Suppose that $\mathrm{Y}$ is not $\mathrm{e}^{*}$-connected. Then there exist disjoint $\mathrm{e}^{*}$-open sets $\mathrm{A}$ and $\mathrm{B}$ of $\mathrm{Y}$ such that $A \bigcup_{B}=\mathrm{Y}$. Since $\mathrm{f}$ is completely $\mathrm{e}^{*}$-irresolute surjective, $f-1(A)$ and $f$ $-1(B)$ are regular open sets in $\mathrm{X}$. moreover, $f-1(A) \cup f$ $-1(B)=X, f-1(A) \neq \varnothing$ and $f-1(B) \neq \varnothing$. This shows that $\mathrm{X}$ is not almost connected, which is a contradiction to the assumption that $\mathrm{X}$ is almost connected. By a contradiction, we have $\mathrm{Y}$ is $\mathrm{e}^{*}$-connected.

\section{Definition}

A topological space $(\mathrm{X}, \mathrm{T})$ is said to be:

1) nearly compact[11] if every regular open cover of $\mathrm{X}$ has a finite subcover;

2) nearly countably compact [12] if every cover by regular open sets has a countable subcover;

3) nearly Lindelof [10] if every cover of $X$ by regular open sets has a countable subcover;

4) $\mathrm{e}^{*}$-compact [13] if every cover of $\mathrm{X}$ by $\mathrm{e}^{*}$-open sets has a finite sub cover;

5) countably $\mathrm{e}^{*}$-compact if every countable cover of $\mathrm{X}$ by $\mathrm{e}^{*}$-open sets has a finite subcover;

6) $\mathrm{e}^{*}$-Lindelof if every cover of $\mathrm{X}$ by $\mathrm{e}^{*}$-open sets has a countable subcover.

\section{Theorem}

If $f:(X, T) \rightarrow\left(Y, T^{*}\right)$ is a completely $\mathrm{e}^{*}$-irresolute surjective function. Then the following statements hold:

1) If $X$ is nearly compact, then $Y$ is $\mathrm{e}^{*}$-compact.

2) If $X$ is nearly Lindelof, then $Y$ is $e^{*}$-Lindelof.

3) If $X$ is nearly countably compact, then $Y$ is countably $\mathrm{e}^{*}$-compact.

Proof. (a). Let $f: X \rightarrow Y$ be a completely $\mathrm{e}^{*}$-irresolute function of nearly compact space $X$ onto a space $Y$. Let $\{U \lambda$ : $\lambda \in \Delta\}$ be any $\mathrm{e}^{*}$-open cover of $\mathrm{Y}$. Then, $\{f-1(U \lambda): \lambda \in \Delta\}$ is a regular open cover of $X$. Since $X$ is nearly compact, there exists a finite subfamily, $\{f-1(U \lambda i): i=1,2, \ldots, n\}$ of 
$\{f-1(U \lambda): \lambda \in \Delta\}$ which cover $\mathrm{X}$. then It follows that $\{U \lambda i$ : $i=1,2, \ldots, n\}$ is a finite subfamily of $\{U \lambda: \lambda \in \Delta\}$ which cover $\mathrm{Y}$. Hence, space $\mathrm{Y}$ is an $\mathrm{e}^{*}$-compact space. The proof of (b) and (c) cases are similar to (a) thus omitted.

\section{N. Definition}

A topological space $(\mathrm{X}, \mathrm{T})$ is said to be:

1) S-closed [14] (resp. e*-closed compact) if every regular closed (resp. $\mathrm{e}^{*}$-closed)cover of $\mathrm{X}$ has a finite subcover;

2) countably S-closed-compact [15] (resp. countably $\mathrm{e}^{*}$-closed compact) if every countable cover of $\mathrm{X}$ by regular closed (resp. $e^{*}$-closed) sets has a finite subcover;

3) S-Lindelof [16] (resp. $e^{*}$-closed Lindelof) if every cover of $\mathrm{X}$ by regular closed (resp. $\mathrm{e}^{*}$-closed) sets has a countable subcover.

\section{O. Theorem}

If $f:(X, T) \rightarrow\left(Y, T^{*}\right)$ is a completely $\mathrm{e}^{*}$-irresolute surjective function. Then the following hold:

1) If $X$ is S-closed, then $Y$ is $e^{*}$-closed compact.

2) If $X$ is $S$-Lindelof, then $Y$ is $e^{*}$-closed Lindelof.

3) If $X$ is countably S-closed-compact, then $Y$ is countably $\mathrm{e}^{*}$-closed compact.

Proof. The proof can be obtained similarly as the Theorem M .

\section{P. Definition}

A topological space $(\mathrm{X}, \mathrm{T})$ is said to be:

1) almost regular [17] if for each regular closed set $\mathrm{M} \subset \mathrm{X}$ and any point $\mathrm{X} \in \mathrm{X} \backslash \mathrm{M}$, there exists disjoint open sets $\mathrm{U}$ and $\mathrm{V}$ such that $x \in U$ and $M \subset V$.

2) Strongly e*-regular if for each $\mathrm{e}^{*}$-closed set $M \subset X$ and for each point $\mathrm{X} \in \mathrm{X} \backslash \mathrm{M}$, there exists disjoint $\mathrm{e}^{*}$ open sets $\mathrm{U}$ and $\mathrm{V}$ such that $x \in U$ and $M \subset V$.

\section{Q. Definition}

A function $f:(X, T) \rightarrow\left(Y, T^{*}\right)$ is called pre-e*-closed if the image of each $\mathrm{e}^{*}$-closed set of $\mathrm{X}$ is an $\mathrm{e}^{*}$-closed set in $\mathrm{Y}$.

\section{R. Theorem}

If a mapping $f:(X, T) \rightarrow\left(Y, T^{*}\right)$ is pre-e*-closed, then for each subset $\mathrm{B}$ of $\mathrm{Y}$ and an $\mathrm{e}^{*}$-open set $\mathrm{U}$ of $\mathrm{X}$ containing $\mathrm{f}$ $-1(\mathrm{~B})$, there exists a $\mathrm{e}^{*}$-open set $\mathrm{V}$ in $\mathrm{Y}$ containing $\mathrm{B}$ such that $f-1(\mathrm{~V}) \subset U$.

Proof. This proof is obvious thus omitted.

\section{S. Theorem}

If $\mathrm{f}:(\mathrm{X}, \mathrm{T}) \rightarrow\left(\mathrm{Y}, \mathrm{T}^{*}\right)$ is completely $e^{*}$-irresolute $e^{*}$-open from an almost regular space $\mathrm{X}$ onto a space $\mathrm{Y}$, then $\mathrm{Y}$ is strongly e*-regular.

Proof. Let $\mathrm{M}$ be an $\mathrm{e}^{*}$-closed set in Y with $y^{\notin} M$. Take $y$ $=f(x)$. Since $\mathrm{f}$ is completely $\mathrm{e}^{*}$-irresolute. Then, $f-1(M)$ is regular closed and so closed set in $X$ and $x^{\notin} f-1(M)$. By almost regularity of $\mathrm{X}$, there exists disjoint open sets $U$ and $V$ such that $x \in U$ and $f-1(M) \subset V$. We obtain that $y=f$ $(x) \in f(U)$ and $M \subset f(V)$ such that $f(U)$ and $f(V)$ are disjoint $\mathrm{e}^{*}$-open sets. Thus, $\mathrm{Y}$ is strongly $\mathrm{e}^{*}$-regular.

\section{T. Definition}

A topological space $(\mathrm{X}, \mathrm{T})$ is said to be:

1) almost normal [18] if for each closed set $A$ and each regular closed set $\mathrm{B}$ such that $\mathrm{A} \cap \mathrm{B}=\varnothing$, there exist disjoint open sets $\mathrm{U}$ and $\mathrm{V}$ such that $A \subset U$ and $B \subset V$.

2) Strongly $e^{*}$-normal if for each pair of disjoint $e^{*}$ closed subsets $\mathrm{A}$ and $\mathrm{B}$ of $\mathrm{X}$, there exist a disjoint $\mathrm{e}^{*}$-open sets $\mathrm{U}$ and $\mathrm{V}$ such that $A \subset U$ and $B \subset V$.

\section{U. Theorem}

If $f:(X, T) \rightarrow\left(Y, T^{*}\right)$ is completely $\mathrm{e}^{*}$-irresolute $\mathrm{e}^{*}$-open from an almost normal space $\mathrm{X}$ onto a space $\mathrm{Y}$, then $\mathrm{Y}$ is strongly e*-normal.

Proof. Let A and B be two disjoint $\mathrm{e}^{*}$-closed subsets in $\mathrm{Y}$. Since $\mathrm{f}$ is completely $\mathrm{e}^{*}$-irresolute, $f-1(A)$ and $f-1(B)$ are disjoint regular closed and so closed sets in $X$. By almost normality of $\mathrm{X}$, there exist disjoint open sets $\mathrm{U}$ and $\mathrm{V}$ such that $f-1(A) \subset U$ and $f-1(B) \subset V$. We obtain that $A \subset f(U)$ and $B \subset f(V)$ such that $f(U)$ and $f(V)$ are disjoint $\mathrm{e}^{*}$-open sets. Thus, $\mathrm{Y}$ is strongly $\mathrm{e}^{*}$-normal.

\section{$V$. Definition}

A topological space $(\mathrm{X}, \mathrm{T})$ is said to be $\mathrm{e}^{*-T} 1$ [8] (resp. $\mathrm{r}$ $\mathrm{T} 1$ [10]) if for each pair of distinct points $\mathrm{x}$ and $\mathrm{y}$ of $\mathrm{X}$, there exist $\mathrm{e}^{*}$-open (resp. regular open) sets $\mathrm{A}$ and $\mathrm{B}$ containing $\mathrm{X}$ and y, respectively, such that $x^{\notin} B$ and $y \notin A$.

\section{$W$. Theorem}

If $f:(X, T) \rightarrow\left(Y, T^{*}\right)$ is a completely $\mathrm{e}^{*}$-irresolute injective function and $\mathrm{Y}$ is $\mathrm{e}^{*}-\mathrm{T} 1$, Then $\mathrm{X}$ is $\mathrm{r}-\mathrm{T} 1$.

Proof. Suppose that $\mathrm{Y}$ is $e^{*}-T 1$. For any two distinct points $\mathrm{x}$ and $\mathrm{y}$ of $\mathrm{X}$, there exist $\mathrm{e}^{*}$-open sets $\mathrm{M} 1$ and $\mathrm{M} 2$ in $Y$ such that $f(x) \in M 1, f(y) \in M 2, f(x) \notin M 2$ and $f(y) \notin M 1$. Since $\mathrm{f}$ is injective completely $\mathrm{e}^{*}$-irresolute function, we have $\mathrm{X}$ is $\mathrm{r}-\mathrm{T} 1$.

\section{Definition}

A topological space $(\mathrm{X}, \mathrm{T})$ is said to be $e^{*}-T 2$ [8] (resp. $r$ $T 2$ [3]) for each pair of distinct points $\mathrm{x}$ and $\mathrm{y}$ in $\mathrm{X}$, there exist disjoint $\mathrm{e}^{*}$-open (resp. regular open) sets $\mathrm{A}$ and $\mathrm{B}$ in $\mathrm{X}$ such that $x \in A$ and $y \in B$.

\section{$Y$. Theorem}

If $f:(X, T) \rightarrow\left(Y, T^{*}\right)$ is a completely $\mathrm{e}^{*}$-irresolute injective function and $\mathrm{Y}$ is $\mathrm{e}^{*}-\mathrm{T} 2$. Then, $\mathrm{X}$ is $\mathrm{r}-\mathrm{T} 2$.

Proof. Similar to proof of Theorem (3.10).

\section{Z. Theorem}

Let $\mathrm{Y}$ be an $\mathrm{e}^{*}-\mathrm{T} 2$ space. Then, the following statements hold:

1) If $f, g:(X, T) \rightarrow\left(Y, T^{*}\right)$ are completely $\mathrm{e}^{*-}$ irresolute functions, then the set $K=\{x \in X: f(x)=$ $g(x)\}$ is $\delta$-closed in $X$.

2) If $f: X \rightarrow Y$ is a completely $\mathrm{e}^{*}$-irresolute function. Then, the set $S=\{(x, y) \in X \times X: f(x)=f(y)\}$ is $\delta$-closed in $X \times X$.

Proof. (a). Let $x \notin K$, then $f(x) \neq g(x)$. Since $\mathrm{Y}$ is $\mathrm{e}^{*}$-T2, Then there exist disjoint $\mathrm{e}^{*}$-open sets $\mathrm{A}$ and $\mathrm{B}$ in $\mathrm{Y}$ such that 
$f(x) \in A$ and $g(x) \in B$. Since $\mathrm{f}$ and $\mathrm{g}$ are completely $\mathrm{e}^{*}$ irresolute functions, then, $f-1(A)$ and $g-1(B)$ are regular open sets. Put $U=f-1(A) \cap g-1(B)$. Then $U$ is a regular open set containing $x$ and $U \cap K \neq \varnothing$. Hence we have $x \notin C l \delta(K)$. (b). the proof is follows from (1).

\section{Characterizations of COMPletely Weakly E*-IRRESOLUTE FUNCTIONS}

In this section, we obtain some characterizations and several properties concerning completely weakly $\mathrm{e}^{*}$ irresolute functions.

\section{A. Definition}

A function $f:(X, T) \rightarrow\left(Y, T^{*}\right)$ is said to be a completely weakly $\mathrm{e}^{*}$-irresolute if for each $\mathrm{x} \in \mathrm{X}$ and for each $\mathrm{e}^{*}$-open set $\mathrm{V}$ containing $f(x)$, there exists an open set $\mathrm{U}$ containing x such that $f(U) \subset V$.

\section{B. Remark}

It is obvious that, every completely $\mathrm{e}^{*}$-irresolute function is completely weakly $\mathrm{e}^{*}$-irresolute and every completely weakly $\mathrm{e}^{*}$-irresolute function is $\mathrm{e}^{*}$-irresolute. But the converses not be true in general as shown in the following examples.

\section{Example}

Let $X=\{1,2,3\}$, Define a topology $T=\{\varnothing, X,\{1\},\{1,2\}$, $\{1,3\}\}$ and $T^{*}=\{\varnothing, X,\{1\},\{1,2\}\}$ on $X$. Then the identity function $f:(X, T) \rightarrow\left(X, T^{*}\right)$ is completely weakly $\mathrm{e}^{*}$ irresolute but not completely $\mathrm{e}^{*}$-irresolute.

\section{Example}

Let $X=\{1,2,3\}$, Define a topology $T=\{\varnothing, X,\{1\},\{1,2\}\}$ and a topology $T^{*}=\{\varnothing, X,\{1\},\{1,3\}\}$ on $X$. Then the identity function $f:(X, T) \rightarrow\left(X, T^{*}\right)$ is e*-irresolute but not completely weakly $\mathrm{e}^{*}$-irresolute.

\section{E. Remark}

From the Remarks of (3.1), (4.1) we obtain Figure (2) shown below:

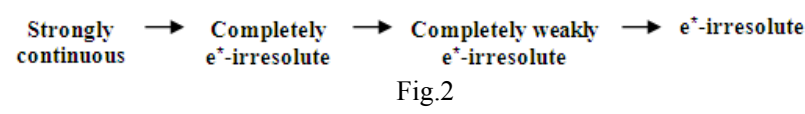

\section{F. Theorem}

For a function $f:(X, T) \rightarrow\left(Y, T^{*}\right)$ the following statements are equivalent:

1) f is completely weakly $\mathrm{e}^{*}$-irresolute;

2) For each $x \in X$ and each $\mathrm{e}^{*}$-open set $\mathrm{V}$ of $\mathrm{Y}$ containing $\mathrm{f}(\mathrm{x})$, there exists an open set $\mathrm{U}$ of $\mathrm{X}$ containing x such that $f(U) \subset V$;

3) $f(C l(A)) \subset e^{*}-C l(f(A))$ for every subset $\mathrm{A}$ of $\mathrm{X}$;

4) $\mathrm{Cl}(f-1(B)) \subset f-1\left(e^{*}-C l(B)\right)$ for every subset $\mathrm{B}$ of $\mathrm{Y}$;

5) For each $\mathrm{e}^{*}$-closed set $\mathrm{V}$ in $\mathrm{Y}, f-1(\mathrm{~V})$ is closed in $\mathrm{X}$;

6) $f-1\left(e^{*}-\operatorname{Int}(B)\right) \subset \operatorname{Int}(f-1(B))$ for every subset $\mathrm{B}$ of $\mathrm{Y}$.

Proof. The proof of this theorem is obvious thus omitted.

\section{G. Theorem}

Let $f: X \rightarrow Y$ be a function. If the graph $g: X \rightarrow X \times Y$ of $\mathrm{f}$ is completely weakly $\mathrm{e}^{*}$-irresolute, then so is $\mathrm{f}$.

Proof. Let V be an $e^{*}$-open subset of $Y$. Then $f-1(V)=g$ $-1(\mathrm{X} \times \mathrm{V})$. Since $\mathrm{g}$ is completely weakly $\mathrm{e}^{*}$-irresolute and $X \times V$ is $\mathrm{e}^{*}$-open in $X \times Y, f-1(V)$ is open in $\mathrm{X}$ and so, $\mathrm{f}$ is completely weakly $\mathrm{e}^{*}$-irresolute.

\section{H. Theorem}

For functions $f:(X, T) \rightarrow\left(Y, T^{*}\right)$ and $g:\left(Y, T^{*}\right) \rightarrow(Z$, $\left.T^{* *}\right)$ the following hold:

1) If $\mathrm{f}$ is completely weakly $\mathrm{e}^{*}$-irresolute function and $\mathrm{g}$ is $\mathrm{e}^{*}$-irresolute. Then, gof: $X \rightarrow Z$ is completely weakly $\mathrm{e}^{*}$-irresolute;

2) If $\mathrm{f}$ is completely continuous and $\mathrm{g}$ is completely weakly e*-irresolute. Then, gof: $X \rightarrow Z$ completely $\mathrm{e}^{*}$-irresolute;

3) If $\mathrm{f}$ is completely $\mathrm{e}^{*}$-irresolute and $\mathrm{g}$ is completely weakly $\mathrm{e}^{*}$-irresolute. Then, gof: $X \rightarrow Z$ is completely $\mathrm{e}^{*}$-irresolute.

4) If $\mathrm{f}$ is completely weakly $\mathrm{e}^{*}$-irresolute function and $\mathrm{g}$ is $\mathrm{e}^{*}$-continuous. Then, gof is continuous.

5) If $\mathrm{f}$ is $\mathrm{e}^{*}$-irresolute and $\mathrm{g}$ is completely weakly $\mathrm{e}^{*}$ irresolute function. Then, gof is $\mathrm{e}^{*}$-irresolute.

6) If $\mathrm{f}$ is continuous and $\mathrm{g}$ is completely weakly $\mathrm{e}^{*}$ irresolute function. Then, gof: $X \rightarrow Z$ is completely weakly e*-irresolute.

Proof. The proof is obvious it is follows from their respective definitions thus omitted.

Recall that a function $f:(X, T) \rightarrow\left(Y, T^{*}\right)$ is said to be almost open if $f-1(V)$ is regular open in $\mathrm{X}$ for every open set $\mathrm{V}$ of $\mathrm{Y}$.

\section{Theorem}

Let $\mathrm{f}:(X, T) \rightarrow\left(Y, T^{*}\right)$ be almost open function and let $g:\left(Y, T^{*}\right) \rightarrow\left(Z, T^{* *}\right)$ be any function such that gof: $(X, T)$ $\rightarrow\left(Z, T^{* *}\right)$ is completely $\mathrm{e}^{*}$-irresolute, then $\mathrm{g}$ is completely weakly e*-irresolute.

Proof. Let $\mathrm{V}$ be an $\mathrm{e}^{*}$-open set in $\left(Z, T^{* *}\right)$. Since gof is completely $\mathrm{e}^{*}$-irresolute, (gof) $-1(\mathrm{~V})=f-1(\mathrm{~g}-1(\mathrm{~V}))$ is regular open in $(\mathrm{X}, \mathrm{T})$. Since $\mathrm{f}$ is almost open surjection, $f(f$ $-1(g-1(V)))=g-1(V)$ is open in $\mathrm{Y}$. Therefore, $\mathrm{g}$ is completely weakly $\mathrm{e}^{*}$-irresolute.

\section{J. Theorem}

Let $f:(X, T) \rightarrow\left(Y, T^{*}\right)$ be open surjection function and let $g:\left(Y, T^{*}\right) \rightarrow\left(Z, T^{* *}\right)$ be any function such that gof: $(X, T)$ $\rightarrow\left(Z, T^{* *}\right)$ is completely weakly $\mathrm{e}^{*}$-irresolute, then $\mathrm{g}$ is completely weakly e*-irresolute.

Proof. Similar to proof of Theorem (4.4).

\section{K. Definition}

A filterbase $£$ is said to be:

$£$-convergent to a point $\mathrm{x}$ in $\mathrm{X}$ if for each $U \in E^{*} \Sigma(X, x)$, there exists $\mathrm{B} \in £$ such that $B \subset U$.

Convergent to a point $\mathrm{x}$ in $\mathrm{X}$ if for each open set $\mathrm{U}$ of $\mathrm{X}$ containing x, there exists $B \in £$ such that $B \subset U$. 


\section{Theorem}

Let $f:(X, T) \rightarrow\left(Y, T^{*}\right)$ be completely weakly $\mathrm{e}^{*}$-irresolute function, then for each point $x \in X$ and each filterbase $-\mathrm{e}^{*}$ - in $\mathrm{X}$ converging to $\mathrm{x}$, the filterbase $f(£)$ is $\mathrm{e}^{*}$-convergent to $\mathrm{f}$ (x).

Proof. Let $\mathrm{x} \in \mathrm{X}$ and $£$ be any filterbase in $\mathrm{X}$ converging to $\mathrm{x}$. Since $\mathrm{f}$ is completely weakly $\mathrm{e}^{*}$-irresolute, then for any $\mathrm{e}^{*}$-open set $\mathrm{V}$ of $\left(Y, T^{*}\right)$ containing $f(x)$, there exists an open set $\mathrm{U}$ of $\mathrm{X}$ containing $\mathrm{x}$ such that $f(U) \subset V$. Since $£$ is converging to $\mathrm{x}$, there exists $\mathrm{B} \in £$ such that $\mathrm{B} \subset \mathrm{U}$. This means that $f(B) \subset V$ and hence the filterbase $f(£)$ is $\mathrm{e}^{*}$ convergent to $f(x)$.

\section{ACKNOWLEDGEMENTS}

I would like to express my sincere gratitude to the referees for their valuable suggestions and comments which improved the paper and I am thankful to professor. D. E. Ekici (Turkey) for sending many of his papers as soon as I had requested and D. Yasir Al-Ani (Iraq) for help.

\section{REFERENCES}

[1] E. Ekici, "On e*-Open Sets and (D, S) ${ }^{*}$-Sets," Math. Moravica, vol. 13, no. 1, pp.29-36, 2009.

[2] S. G. Crossley and S. K. Hildebrand, "Semi Topological properties," Fund. Math, vol. 74, pp. 233-254, 1972.

[3] N. Rajesh, "Two new types of irresolute functions via b-open sets," Acta. Math. Hungers, vol. 27, pp. 287-297. 2012.
[4] N. V. Velicko, "H-closed topological spaces," Amer. Math. Soc. Trans, vol. 78, no. 2, pp. 103-118, 1968

[5] M. H. Stone, "Applications of the theory Boolean rings to general topology," Trans. Amer. Math. Soc, vol. 41, pp. 375-381, 1937.

[6] N. Levine, "Strong continuity in topological spaces," Amer. Math. Monthly, vol. 67, pp. 269, 1960.

[7] S. P. Arya and R. Gupta, "On strongly continuous maps," Kyungpook Math. J, vol. 14, pp. 131-143, 1974.

[8] E. Ekici, "New forms of contra-continuity," Carpathian J. Math. Vol. 24, no. 1, pp. 37-45, 2008.

[9] P. E. Long and L. L. Herrington, "Basic properties of regular-closed functions," Rend. Circ. Mat. Palermo, vol. 27, pp. 20-28, 1978.

[10] E. Ekici, "Generalization of perfectly continuous, Regular setconnected and clopen functions," Acta. Math. Hungar, vol. 107, no. 3, pp.193-206, 2005.

[11] M. K. Singal, A. R. Singal, and A. Mathur, "On nearly compact spaces," Boll. UMI, vol. 4, pp. 702-710, 1964.

[12] N. Ergun, "On nearly paracompact spaces. Intanbul. Univ. Fen. Mec. Ser," vol. 45, pp. 65-87, 1980

[13] E. Ekici, "Some generalizations of almost contra-super-continuity," Filomat, vol. 21, no. 2, pp. 31-44, 2007.

[14] T. Thomson, "S-closed spaces. Proc. Amer. Math. Soc," vol. 60, pp. 335-338, 1976.

[15] M. E. A. E. Monsef, S. N. E. Deep, and R. A. Mohmoud, " $\beta$-open sets and $\beta$-continuous mappings," Bull. Fac. Sci. Assint Univ, vol. 12, pp. 77-90, 1989.

[16] G. D. Maio, "S-closed spaces, S-sets and S-continuous functions," Acad. Sci. Torino, pp.125-134, 1984.

[17] M. K. Sindal and S. P. Arya, "On almost regular spaces. Glasnik Mat," vol. 4, no. 24, pp. 89-99.

[18] M. K. Sindal and S. P. Arya, "Almost normal and almost completely regular spaces. Glasnik Mat," vol. 5, no. 25, pp. 141-152, 1970. 